\title{
Developing Students' Curiosity Through Chemistry Hands-on Activities: A Case of Selected Community Secondary Schools in Dar es Salaam, Tanzania
}

\author{
Esther Samwel Kibga ${ }^{1 *}$, Emmanuel Gakuba ${ }^{2}$, John Sentongo ${ }^{3}$ \\ ${ }^{1}$ University of Rwanda-College of Education (African Center of Excellence for Innovative teaching of Mathematics and Science, \\ RWANDA \\ 2 University of Rwanda-College of Education (UR-CE), P.O Box 55 Rwamagana, RWANDA \\ ${ }^{3}$ Makerere University, Department of Science, Technical and Vocational Education (DSTVE), P.O. Box 7062 Kampala, UGANDA
}

Received 25 September 2020 - Accepted 28 March 2021

\begin{abstract}
Curiosity is the inner drive for learning or 'hunger for learning' which is among the twenty-firstcentury learning competencies. Students in their earliest stage ought to exhibit curiosity to stirup knowledge acquisition and exploration, yet the development of curiosity in the context of education is considered to be unusual. This research assesses how chemistry students develop and express curiosity in a hands-on learning environment. A sample of 169 senior three students from three community secondary schools in Dar es Salaam was involved in this study. Besides, the study examined how hands-on activities in chemistry lessons can be incorporated as a pedagogical practice to foster students' curiosity. The study employed a convergent mixed method design in (QUAL+quant) form following a pragmatic stance. We used lesson observations, interviews, and Focus Group Discussions (FGDs) to gather qualitative data while quantitative data were obtained through the Students' Self-Reporting Questionnaire (SSRQ) and Teacher Rating Scale (TRS). It was revealed that hands-on activities can successfully be used when teachers share success criteria and learning intentions of a particular lesson. The overall results showed a significant increase in students' curiosity due to the implementation of hands-on activities as an instructional strategy. In this perspective, we advocate for hands-on activities to be used frequently in chemistry lesson sessions and more studies should be done further on students' curiosity in the field of education.
\end{abstract}

Keywords: hands-on activities, home-based materials, students' curiosity, and learning of chemistry

\section{INTRODUCTION}

Teaching students should be focused on the way that they can develop and express their learning curiosity particularly in the learning of chemistry. Pluck and Johnson (2011) in 'stimulating curiosity to enhance learning' highlight that curiosity combined with the motivation to learn is more important than intelligence. According to Zion and Sadeh (2007), students' curious mind fosters the learning of abstract and complex concepts. Oudeyer, et al. (2016) defines curiosity as a desire for active learning, spontaneous exploration, and find out. Borowske (2005) and Ostroff (2016) highlight the basic role of curiosity in learning is to encourage and create knowledge. Therefore, by considering the significant role of curiosity in learning, the development of students' curiosity should be among the major focuses of teaching and learning process.

Chemistry, organic, inorganic, and physical would be more difficult to deliver if the application and real-life context are less obvious. According to Hirça (2013) and Holstermann, Grube, and Bögeholz (2010), students learn science when they directly experience the method and the process of inquiry. Hirça (2013) pointed out that students can learn better when they measure, touch, feel, make charts, manipulate, draw, and record data. These are among the important aspects of learning instruction known as hands-on activities. Hirça (2013) highlights

(c) 2021 by the authors; licensee Modestum. This article is an open access article distributed under the terms and conditions of the Creative Commons Attribution License (http://creativecommons.org/licenses/by/4.0/). 


\section{Contribution to the literature}

- Curiosity is an important learning skill that is bypassed in the context of education. Thus, this research study aimed to improve students' curiosity through hands-on activities performed using materials available in students' immediate resources.

- The study provides constructive information to educators as well as science teachers especially those who teach chemistry on the use of low-cost teaching aids as well as the use of hands-on activities to improve teaching practices.

- The study proposes and recommends further on the use of the designed intervention in an education setting of similar context.

further that an impactful learning environment ought to allow students to learn by doing practice. Moreover, this in line with John Dewey in (Sikandar, 2016) who highlighted that learning by doing stirs various learning skills including curiosity. Thus, engaging learners in various hands-on activities motivate their curiosity to learn new skills and knowledge through their experiences fully.

Besides, scholars (Jirout \& Klahr, 2012; Kashdan et al., 2004; Lamnina \& Chase, 2019; J. Litman, 2005), identified different kinds of curiosity namely; openness to experience, epistemic curiosity, need for cognition, perceptual curiosity, typical intelligence engagement. However, only epistemic and perceptual curiosities are discussed regarding the focus and context of this research. According to Von Stumm and colleagues, epistemic curiosity is referred to as, the individual difference in seeking out for engagement and acquires knowledge (Von Stumm et al., 2011); whereas perceptual curiosity is induced by visual, auditory, and physical stimulation towards experience and feel (Pluck \& Johnson, 2011; Von Stumm et al., 2011). Hence, to satisfy curiosity, the inquiry should involve activities and skills but should focus on the active search for knowledge and understanding of unusual elements in the environment.

It is assumed that working in a hands-on way 'learning by doing' provides a more realistic and exciting experience of the content. Holstermann et al. (2010) identify experimentation, manipulation of symbols and objects as well as students' interaction to be among students' hands-on activities which can support meaningfully the learning of chemistry. They further indicated that the respective activities vary on how they enhance learning. Therefore, learning of the content can be strengthened when a student experiences a learning activity as enjoyable, pleasant, stimulating, and important.

Despite its importance in education, particularly chemistry classrooms, the research on development of students' curiosity is somewhat limited. Much bodies of research about curiosity were done around the mid-19th century but was mostly on human psychology. Curiosity was strictly linked to biological drives, such as hunger and thirst (Pluck \& Johnson, 2011). According to Pluck and Johnson (2011), for learning to take place an organism must be motivated by being in a state of deprivation, such as being hungry or thirsty. Therefore, a good interpretation of human behaviour and learner curiosity is needed especially in a range of educational contexts.

However, the Government of Tanzania has shown a serious commitment to achieving Education for All (EFA) through its poverty reduction strategy which led to the introduction of Secondary Education Development Programmes (SEDP I of 2006 and SEDP II of 2010). The Ministry of Education and Vocation Training through SEDPs had four thematic areas outlined in its Education Strategic Plan (ESP) in achieving the MDGs (MOEVT, 2010). These areas include the provision of quality education, enrolment expansion and access, equity, and efficiency in the management of secondary schools. These areas are also stipulated in the Education and Training Policy (ETP) of 2014 (URT, 2014). Also, the Sustainable Development Goals of 2015 specifically SDG4 emphasize the provision of quality education. Not only that but most of the interventions, projects, and different programs are implemented to improve the quality of education (Galabawa, 2008) especially the provision of quality science education.

Despite these efforts of the government, Galabawa argues that still there is a long journey to achieve quality education in community secondary schools. A report by Hakielimu (2017) has shown that there is an enormous gap that prevails between the number of students graduating from Community schools and those among them who can master a minimum set of cognitive skills. Machumu (2011) argued that community secondary schools have mainly been facing challenges due to the acute shortage of qualified teachers, poor school infrastructures, and inadequate teaching and learning materials. These are some of the motives which draw the attention of research, especially in community secondary schools.

\section{Statement of Problem}

Amongst the challenges that hinder the provision of quality science education in community secondary schools in Tanzania, are inadequate teaching and learning materials as well as inappropriate instructional 
strategies used to facilitate learning. The inappropriateness may result in students lacking noncognitive learning skills like curiosity. Nonetheless, students' curiosity is evidently among the core determinants of individual differences in academic achievement yet still overlooked. Also, research on this topic specifically in the education context has slowly been developed and curiosity is mostly considered to be a psychological aspect. Thus, hands-on activities using low-cost materials from students' immediate environment is seen to be one of the possible interventions to practically overcome the inappropriateness of the instructional strategy as well as the inadequacy of teaching and learning materials in chemistry lessons in community secondary schools. Consequently, the use of hands-on activities can enable students to acquire curiosity as one required basic learning skills in science in general and chemistry in particular.

\section{Research Questions}

This research was guided by the following research questions:

1. How do hands-on activities performed using learning aids designed by the students stimulate their curiosity during chemistry lessons?

2. What learning aids can students design from lowcost materials which can enhance the learning of chemistry?

3. How can hands-on activities in chemistry lessons be incorporated as a pedagogical practice to foster students' curiosity?

\section{THEORETICAL FRAMEWORK}

This work was guided by the pragmatic theory of education proposed by the American psychologist and philosopher John Dewey (1859-1952) as well as Vygotsky's (the 1920s) socio-cultural zone of proximal development (ZPD) view. In pragmatism, Dewey emphasizes learning by doing whereby the transfer of knowledge occurs through meaningful and spontaneous activities of a student (Sikandar, 2016). Dewey rejected the traditional way of teaching in which students are considered to be passive objects while a teacher is the one who is knowledgeable and authoritative (Glassman, 2001; Khasawneh et al., 2014). Pragmatic forms of education enable students to learn through interaction by sharing experiences from their society. Moreover, learning through sharing such experiences may raise the students' curiosity, hope, and gives them a purpose to carry out lesson activities (Sikandar, 2016). That is why Dewey considered learning experiences as the most important determinant of students to explore their environment because students are naturally curious. Therefore, monitoring the experiences that students encounter in the process of learning is considered to be one of the most important ways to stir-up students' curiosity.

These experiences are considered to be students' prior knowledge before instruction. However, in Vygotsky's ZPD, the role of a teacher is to value students' experiences and guide them to intellectual maturity (Fani \& Ghaemi, 2011). According to Fani and Ghaemi (2011), ZPD is identified as the point where learning takes place and each student has his or her ZPD. Also, Affine (2012) highlights further that individual students' ZPD can be identified by the teacher making a close examination of each student as an individual learner. Again, Fani and Ghaemi (2011) suggest that when the teacher arranges for classroom instruction he/she should include clear goals and objectives, promote inquiries and discussions as well as allow movements in the classroom. Therefore, collaborative and interactive sharing of experience among students should be done under teacher guidance to maximize learning and improvement of students' curiosity.

\section{METHODOLOGY}

\section{Research Design}

A convergent mixed methods research design (Creswell, 2014) was employed, taking a pragmatic stance. While qualitative data were collected using interviews, lesson observations, and focus group discussions, quantitative data were collected via questionnaires by employing a one-group pretestposttest research design. "The intent may be to seek a common understanding through triangulating data from multiple methods or to use multiple lenses simultaneously to achieve alternative perspectives that are not reduced to a single understanding" (Mertens, 2010 , p. 294). However, researchers recommend the use of pragmatism as the appropriate philosophical orientation to guide mixed methods researchers (Goldkuhl, 2012; Mertens, 2010; Morgan, 2014) because the researcher retains both the subjective and objective epistemological view of the research problem. Also, pragmatic philosophers believe that the monoparadigmatic orientation of research cannot be enough to understand human behaviours (Goldkuhl, 2012; Morgan, 2014; Shannon-Baker, 2016). Therefore, pragmatism allows for a research design and methodologies that are best suited to the purpose of the study.

\section{Research Participants and Content Selection}

Basing on the purpose of this work a total of 169 students (101 boys, 60\% and 68 girls, 40\%) were purposively selected for this study from three senior three science classes in three community secondary schools. These students were selected because they were assumed to certainly provide enough information 
(Mertens, 2010; Yin, 2009) to answer the research questions as they were due to learning the mole concept and volumetric analysis during the research period. Mole concept and volumetric analysis were selected because they provide the basic foundation to other physical chemistry topics and yet proven to be the most challenging topics (Lee et al., 2001) to students at this level. The participants of this research project had a mean age of 16.12 with a standard deviation of 0.854 . In addition to that, three chemistry teachers (one male and two females) with an average teaching experience of five years were also active participants in this research project. These three community schools were also purposively selected from 142 public schools in Dar es Salaam, which is the business capital city of the United Republic of Tanzania and bears a larger population of the country. Among 142 public schools, 132 are community schools while only 10 schools are considered to be non-community schools constructed after independence. Therefore, the sampled research participants were obtained from three of 132 community schools.

\section{RESEARCH INSTRUMENTS}

\section{Lesson Observation Schedule}

The observation schedule was divided into subsections that included Planning, teaching strategy, learning resources, learning and development of learners' curiosity, as well as the learners' ability to develop the instructional materials (Appendix A). Under the first sub-section, we observed the way lessons on mole concept and volumetric analysis were planned and introduced to the students using a competency-based curriculum. In the second sub-section, we observed the strategies that teachers used to deliver and facilitate the learning process. Chemistry lessons were also observed to gather non-verbal expressions, as well as determining the extent to which students engage themselves in hands-on activities during chemistry lessons.

A total of 42 lessons (14 lessons in each school) were observed in all three schools, where 14 lessons of the total were single (40 minutes) while 18 lessons were double (80 minutes). Lesson observations were conducted as recommended by Creswell (2014), and Houghton et al. (2013), who contend that the researcher should act as a non-participatory observer to avoid influencing the process of data collection.

\section{Focus Group Discussions (FGDs) Guide}

Although the study targeted chemistry concepts, the questions asked in student's FGDs were not chemistry content-based. Instead, they were based on instructional strategies and resources that can enhance active learning among Ordinary Level chemistry students. FGDs guide was semi-structured (Mertens, 2010) to ensure flexibility and consisted of 7 questions. FGDs are highly advocated to be used with students because it enables the research participants to be comfortable and relaxed while in the company and they feel secure (Krueger \& Casey, 2002; McLafferty, 2004). FGDs are highly advocated to be used with students because it enables the research participants to be comfortable and relaxed while in the company and they feel secure (Krueger \& Casey, 2002; McLafferty, 2004)

The FGDs were conducted once a week after lesson observation in the convenience of the research participants and a total of 21 FGDs interviews were conducted in all three schools, seven per school. Each FGD comprised of six Students and lasted for approximately $30-45$ minutes on average and this time was considered sufficient to reduce initial anxiety (Shahid et al., 2009). All FGDs were audio-recorded and helped researchers to elicit students' experiences during the chemistry lessons. During FGDs, the researchers got the opportunity to discuss the ways through which teaching using locally made materials could be done better to enhance active learning with students and hence develop their curiosity. FGDs is highly advocated for to be used with students because it enables the research participants to be comfortable and relaxed while in the company.

\section{Interviews Guide}

The interview guide was semi-structured and checked for accuracy (Baxter \& Jack, 2008; Yin, 2009), by qualitative research experts. The interview guide comprised of seven questions which were complemented with the probing questions to ensure flexibility of research participants and the data collected. Also, the interviews were done specifically for teachers, once per week after lesson observation and a total of 21 interviews were conducted in all of the three schools. All interview session were audio recorded and additional field notes were taken. In the teacher interview, the researcher got a chance to do some mentorship to teachers $\mathrm{A}, \mathrm{B}$, and $\mathrm{C}$ regarding the intervention.

\section{Students Self-Reporting Questionnaires (SSRQ)}

Students' self-reporting questionnaire SSRQ on their curiosity was adapted from (Olson, 1986) (Appendix B). However, studies were done on students' curiosity highly consider the psychological aspect of a student (Litman, 2005; Litman \& Spielberger, 2003; Pluck \& Johnson, 2011) by focusing on aspects like thirsty and hunger. Pluck and Johnson (2011) demonstrated that for learning to take place an organism must be motivated by being in a state of deprivation, such as being hungry or thirsty. Most studies done on students' curiosity were not seen to match with the focus of this study. This is why the SSRQ designed by Oslon in 1986 was seen to be appropriate to the context of this despite of it being 
ancient. Besides, the SSRQ was validated by doing a pilot study in one school of a similar context with the schools involved in this study. The Cronbach Alpha coefficient value of 0.83 was obtained.

\section{Teacher Rating Scale (TRS)}

The teacher rating scale TRS on students' curiosity was also adapted from (Olson, 1986) to triangulate the information given by the students in the SSRQ. This questionnaire had two parts whereas; the first part required the teacher to give demographic information about the class, and the second part comprised of the definition of students' curiosity which guided the teacher to rate the students' curiosity on different levels. According to Maw and Maw in Olson (1986), a learner is said to exhibit curiosity to the degree that:

1. Reacts positively to new, incongruous, or mysterious elements in the environment by moving toward them, by exploring them, or by manipulating them,

2. Exhibits a need or a desire to know more about himself and/or his environment,

3. Scans his surroundings seeking new experiences, and

4. Persists in examining and exploring a problem and to know more about it.

The second part had a rating scale where the teacher was supposed to rate individual students based on the given definition of students' curiosity. According to the definition given on curiosity, learners' curiosity was supposed to range from; (1) not curious at all, (2) somewhat curious, (3) moderately curious, (4) very curious, (5) and extremely curious (Appendix C). To obtain rigorous information the teacher was supposed to have a better understanding of all students at the individual level. However, the rating scale was piloted to establish its reliability to 22 students from a school with a similar learning environment and context. A Cronbach Alpha coefficient value of 0.72 was obtained and it was considered to be acceptable since it was greater than 0.70 which is the threshold recommended by Taber (2018).

\section{Trustworthiness and Rigor of Research Instruments}

Since the study was majorly qualitative, several majors were taken into consideration to ensure the information obtained from the project is transferable, credible, dependable, and confirmable. The study was done in the real-world environment, therefore the information obtained from this research project can be transferable to other educational contexts with similar situations, populations, and similar phenomena (Cohen et al., 2007; Creemers et al., 2010). The observation schedule, interview, and FGD guides were checked for credibility by two experienced science educators (E. G. \& J. S.) to establish their inter-rater reliability, worthiness to yield credible outcomes, and their recommendations were affected before data collection after the researchers reach consensus.

Besides, the researchers ensured conformability of the information obtained (Basit, 2003; Yin, 2009). This was done by ensuring the research findings are based on participants' responses, with no personal motivation or potential biases from the researcher. Audit trails were done throughout the data analysis process to ensure the study findings portray accurately the respondents' responses (Kelly \& Lesh, 2000; Yin, 2009). Moreover, the researchers maintained the dependability of the study to ensure the reliability and trustworthiness of the research findings (Creemers et al., 2010), and the study can be replicated by other researchers in other educational contexts with a similar environment. Finally, triangulation of the information obtained from the observation schedule, interview, and FGD guides, as well as SSRQ and TRS (Cohen et al., 2007; Creswell, 2014; Mertens, 2010; Yin, 2009), was ensured to maintain credibility and accuracy of the research findings (Creswell, 2014; Mertens, 2010; Yin, 2009).

\section{Data Collection Procedures}

At the beginning of the data collection process, both students and teachers were given a brief about this research project. They got an opportunity to go through the research information sheet and filled the consent forms to voluntarily participate in the study. Then, the researcher administered a pre-test-SSRQ to monitor the level of their curiosity before the intervention. Apart from that, the researcher gave a pre-test-TRS to chemistry teachers who were part of the study to rate the curiosity level of their students at the onset of the study. Besides, the information obtained from both pre-testSSRQ as well as pre-test-TRS were analyzed and used to inform the designed intervention which was intended for this study. Then, the three chemistry teachers went through a workshop discussion on the use of hands-on activities and planned for the entire application of the intervention in their classroom settings. Finally, the students were oriented on the intervention and the process of data collection commenced.

The study was conducted in 2019 from March to June. It was done in two phases whereas PHASE I was done in four weeks with a total of twenty-four lesson observations in all three schools. At the end of the first phase teachers met for one day for the refinement of the intervention. Thereafter, both the researcher and the teachers evaluated the trend of the intervention and contributed to knowledge on its recap for the next phase. PHASE II was done in three weeks and the number of school visits for lesson observation was eighteen in total. This corresponds to two lesson observations per school every week for all seven weeks of the data collection process. All the lesson observation was done to monitor the verbal and non-verbal interactions between students 
in hands-on activities of chemistry lessons that could result in the development of students' curiosity (Bufkin, 2006; Kitzinger, 1995; Yin, 2009). On top of that, each week the researcher got time to do one face-to-face semistructured interview session with senior three chemistry teachers and one FGDs session with some selected students.

Apart from the semi-structured interview guide, the researcher used probing questions to aid mentorship to teachers $\mathrm{A}, \mathrm{B}$, and $\mathrm{C}$ based on the designed intervention. Also, in FGDs the researcher got the opportunity to discuss with students on better ways through which hands-on activities could be done to develop their learning curiosity. In addition to that, in the chemistry lessons observation, the following were the indicators of learners' curiosity that were observed: (1) inquiry about information or given problem, (2) desire and want to find out details, (3) enthusiasms/motivation in learning, (4) searching for information from various source, (5) trial of alternative problem-solving and ability to explore. These indicators were also considered in the analysis of the SSRQ results.

Also, apart from the information obtained using the observation schedule, extensive field notes were taken to give information about the verbal and no-verbal interactions between students, students' behaviours in the lesson, description of the physical environment, as well as how students were active or inactive in chemistry lessons. At the end of the data collection process, the same questions which appeared in both pre-test-SSRQ were administered again to the same group of participants as the post-test-SSRQ. Also, teachers had to rate their students using the post-test-TRS as it was in pre-test-TRS. The post-tests were done to assess the development of students' curiosity that would be due to the emphasis on the use of hands-on activities in chemistry lessons.

\section{Data Analysis}

In the analysis of qualitative data, the researcher considered thematic procedures of data analysis as proposed by Yin (2009), in form of preliminary and retrospective analysis. The preliminary analysis was done to analyse the pre-test-SSRQ and TRS results to obtain qualitative information which informed the design of the intervention. Besides, the retrospective analysis was performed on the information obtained daily from lesson observation, field notes, and the audio recorded information from interviews and FGDs. Nonetheless, descriptive (mean and standard deviation) as well as inferential (dependent samples $t$-test and effect size) statistical data were obtained for quantitative instruments used (Creswell, 2008).

In the thematic analysis of qualitative data, the audio data from teacher interviews and FGDs were transcribed and later translated (only the information which was obtained in the Swahili language). The transcribed information together with the field notes was organized and read through to obtain information that was later grouped into themes and sub-themes (Mertens, 2010; Yin, 2009) basing on the research questions. Also, the entire coding process was done by one of the researchers in the research team whereas the other two researchers did the rating to assess the accuracy of the information obtained. Then, important information that contributes to the study findings was obtained depending on the purpose of the study.

However, quantitative data analysis was aided by using Statistical Package for Social Scientists (SPSS) software version 20 and Microsoft excel 2010. Also, the dependent sample $t$-test on pre- and post-intervention SSRQ and TRS were meant for checking the level of students' curiosity before and after the intervention. The effect size quantified the difference in pre- and postintervention $t$-test results for both SSRQ and TRS. Besides, triangulation of the information obtained from qualitative and quantitative data was done to obtain overall meaningful information from this research project about the development of students' curiosity.

\section{RESULTS}

\section{Research Question 1}

We triangulated data obtained from lesson observations, teacher interviews, and FGDs responses to answer research question 1 through establishment of information that tells how hands-on activities are applied in Chemistry Lesson Sessions

Assessment of how hands-on activities can stimulate students' curiosity was done through lesson observation complemented with teacher interviews as well as students' FGDs. The results indicate that despite both teachers and students have gone through some orientation and mentorship on the use of hands-on activities in chemistry lessons, but lesson observations done in the first week after the emphasis on the use of this instruction strategy indicate the response to be poor. For instance: in one of the classroom observations in School C, the teacher was facilitating volumetric analysis specifically acid-base titration. In the session, the emphasis was more on the colour change when an indicator is dropped in a beaker containing an alkaline solution and the colour change that occur on neutralization by the addition of the acidic solution. The teacher was observed to dominate the lesson and he was the only one talking while students were listening and take notes. The interaction of students in activities that could facilitate the learning of the content was negligible. This signifies that before the intervention the use of hands-on activities in chemistry lesson sessions was misinterpreted by both students and teachers. In this 
regard, both the teacher and students imagined handson activities to only mean experimentation.

The teacher thought that to make hands-on activities effective in his lesson, it is necessary to bring the apparatus from the laboratory to the classroom session for the students to go through experimentation in their respective classrooms. This was confirmed through the expression given by the teacher and students in both the interview and the FGDs respectively.

For instance, Gerald (students' pseudonym) said in one of FGDs: "normally in chemistry periods...we listen to what our teachers teach, write notes and sometimes discuss on our desks".

Another student Tarlick complemented the statement given by Gerald and said: "Mostly our chemistry teachers come in the class to teach and give us notes only... by the way do you think it is possible to do the activities you proposed in the class while we are many like that!"

But through continuous mentorship and the school visits done, the research participants realized the essence of hands-on activities and the possible impact on the learning process.

Apart from that, teachers thought that getting students involved in the learning process could be challenging and could interfere with their planned scheme of works. The most prominent reason given by teachers was on their prior understanding that mostly learner-centered approaches are time-consuming because they require learners to take charge of their learning. In the interviews with teachers on different occasions, teachers $\mathrm{A}$ and $\mathrm{C}$ gave their views on this matter

Teacher A said: "you know we have a lot of content to be covered....if students are involved in the process of teaching, you may find yourself not covering what you intended to teach".

This claim in line with what Teacher C said: "I am aware of this strategy but if you try to allow students to get involved in the lesson, plenty of time is consumed and one is likely not to be able to cover the intended content".

Again teacher A added on this claim: "Our students normally rely on what we teach them. Sometimes you give them the chance to be involved in the learning process but they take too much time to think and sometimes they just keep quiet without giving you an answer."

The above information reveals the major concern of teachers to be time constraints, that much time is required to allow all students to settle and enhance their awareness of the activities to be done as well as the content to be learned.

Besides, a positive response was observed few weeks after the intervention. With time students' interaction in chemistry lessons increased and both their posture, gestures portrayed this improvement. Students were observed to move around the class freely and whenever they see any object which draws their attention they preferred touching it rather than only looking at it. Also, both students and teachers seemed to enjoy the lesson and students' interaction in hands-on activities increased. The results from both teachers' interviews and FGDs confirmed this change.

Teachers B said that: "engaging students in lesson activities enable them to take part in the learning process which also reduces our workload".

Apart from that students emphasized that: "teachers should continue to motivate us to participate in learning activities so that we can help one another to understand the lesson content".

This claim can be true because normally classes bear students of different learning abilities. Therefore, the statements given by both students and teachers give clues on how the implementation of hands-on activities in chemistry lessons was impactful on the active engagement of students in the lesson, and later on students' learning curiosity.

\section{Research Question 2}

We triangulated data from lesson observations, teacher interviews, and students FGDs to answer question number 2 through establishment of information about instructional materials designed by students to stimulate their curiosity.

It was observed from the study that when students get proper and better teacher guidance, they fully engage themselves in hands-on activities as well as search for quality instructional materials. Students managed to make some locally made apparatus using home-based materials. Also, students used materials like empty water bottles of different sizes, syringes of different sizes, rubber bands, and clothes pegs to make local apparatus to be used to learn volumetric analysis. Some of these apparatus were like beaker, burette, droppers, and funnels whereas some are represented in (Figure 1). With the apparatus made by the students, teachers could prepare some solutions for simple experiments on titration, and students did experiments in their corresponding groups during chemistry lessons. Therefore, the speculation obtained from this finding is that the ability of learners to search and designing of instructional materials, as well as better engagement in hands-on activities, partly depends on teacher guidance.

This was also verified in FGDs done between the researcher and the students. The discussion was as follows:

Researcher: "what can you say about you searching for your learning materials?"

Amina: "it is good...because we can know what we will learn even before the teacher comes in the class....in this system of learning the desire of knowing what is going to be learned must increase otherwise you can find yourself different from others in the class" 


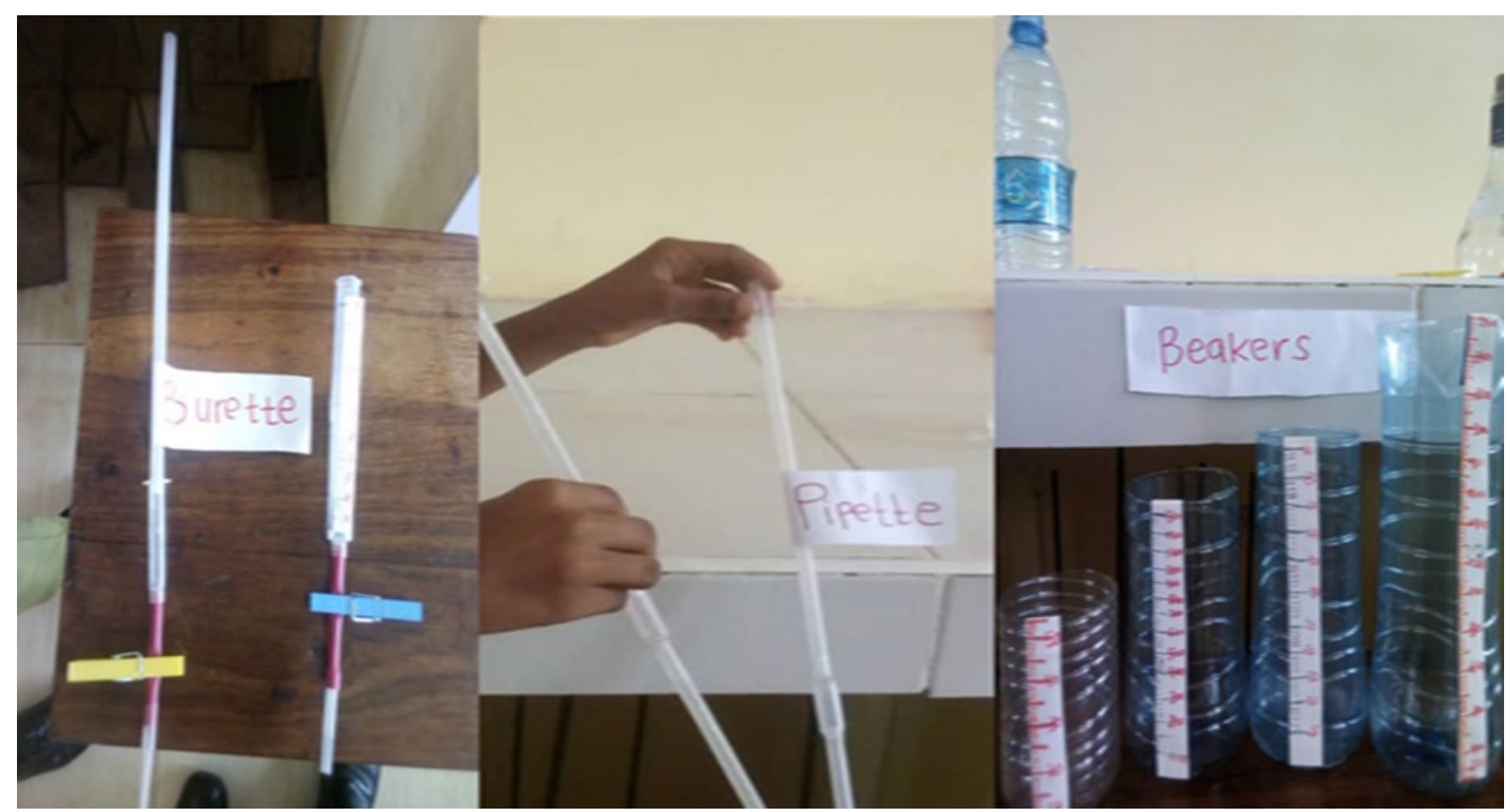

Figure 1. Samples of Burette, Pipette, and Beakers locally made by students

Researcher: Can you tell me more about how you find yourself different from others

Amina (continued): ...imagine others are participating in answering questions asked by the teacher and you have nothing to contribute.... or your fellows are working in their groups and you do not participate fully.... you cannot participate without knowing what you are supposed to do"

Puljet: "for me, I can say that...it is good experiences ...I now understand that there materials which can enhance my learning which I ignored before".... these days when I see objects they draw my attention and I won't be satisfied only by looking at them.

Researchers' follow-up question: "can you mention some of those materials?"

Puljet: "Yes there many things in around the school and at our home which can be used to learn chemistry"

Kengwa: "for example.... empties bottles and tins, pegs..... and so many others"

The results from FGDs with students revealed that the desire for learning increased more as the use of instructional materials self-designed by students in chemistry lessons was emphasized. The materials made by students were employed whenever necessary within the lesson episode in various hands-on activities. Besides, hands-on activities were mostly done in groups of not more than six students whereby individual students participated in different activities within a respective lesson by cooperating with their fellow students. In these groups, students manipulated different learning aids related to particular chemistry content. For instance, in one of the lessons on volumetric analysis, students in their respective groups discussed the use of different locally made apparatus.

\section{Research Question 3}

We triangulated data from SSRQ and TRS to establish the extent in which hands-on activities can develop students' curiosity.

The qualitative findings were complemented by the quantitative part of the study which involved mainly two instruments such as the curiosity SSRQ and the curiosity TRS adapted form (Olson, 1986). The SSRQ had 30 items selected to check on students' curiosity in the context of this research study. These items were further categorized to give five indicators of curiosity as it is shown in Table 1. Also, the table indicates the mean and standard deviations of pre-test and post-test for each indicator.

Also, the result indicates a substantial increase in the normalized gain ( $\mathrm{N}$-gain) of both mean and standard deviation for the five indicators of curiosity as follows: Inquiry about information or given problem ( $\mathrm{N}$-gain Mean $=0.7, N$-gain $S D=0.3)$, Desire and want to find out details $(N$-gain Mean $=0.9, N$-gain $S D=0.3)$, Enthusiasms / motivation in learning $(N$-gain Mean $=0.5$, $N$-gain $S D=0.2)$, Searching for information from various source $(N$-gain Mean $=0.9, N$-gain $S D=0.2)$, and Trial of alternative problem-solving and ability to explore ( $N$ gain Mean $=0.7, N$-gain $S D=0.2$. . This information is well described in Figure 2 which is the graphical representation of normalized gain results, whereas indicators 2 and 4 show the profound gain than indicators 1,3 , and 5 . 
Table 1. A table of Descriptive Statistics of the grouped indicators obtained from a curiosity self-reporting questionnaire (SSRQ)

\begin{tabular}{|c|c|c|c|c|c|c|c|}
\hline \multirow[t]{2}{*}{ Indicators } & \multirow[t]{2}{*}{ Statement number } & \multicolumn{3}{|c|}{ Average mean } & \multicolumn{3}{|c|}{ Standard deviation } \\
\hline & & Pre-test & Post-test & N-Gain & Pre-test & Post-test & N-Gain \\
\hline $\begin{array}{l}\text { Inquiry about information or a given } \\
\text { problem }\end{array}$ & $4,10,12,17,21,29$ & 3.34 & 4.06 & 0.7 & 0.71 & 0.44 & 0.3 \\
\hline Desire and want to find out details & $3,7,8,11,22$ & 3 & 3.83 & 0.9 & 0.74 & 0.41 & 0.3 \\
\hline Enthusiasm/motivation in learning & $2,9,19,26,28,30,13$ & 2.91 & 3.38 & 0.5 & 0.45 & 0.27 & 0.2 \\
\hline Search for information from various source & $5,15,20,24,25$ & 3.25 & 4.09 & 0.9 & 0.65 & 0.44 & 0.2 \\
\hline $\begin{array}{l}\text { Trial of alternative problem-solving and } \\
\text { ability to explore }\end{array}$ & $1,6,14,16,23,27,18$ & 3.32 & 3.99 & 0.7 & 0.56 & 0.35 & 0.2 \\
\hline
\end{tabular}

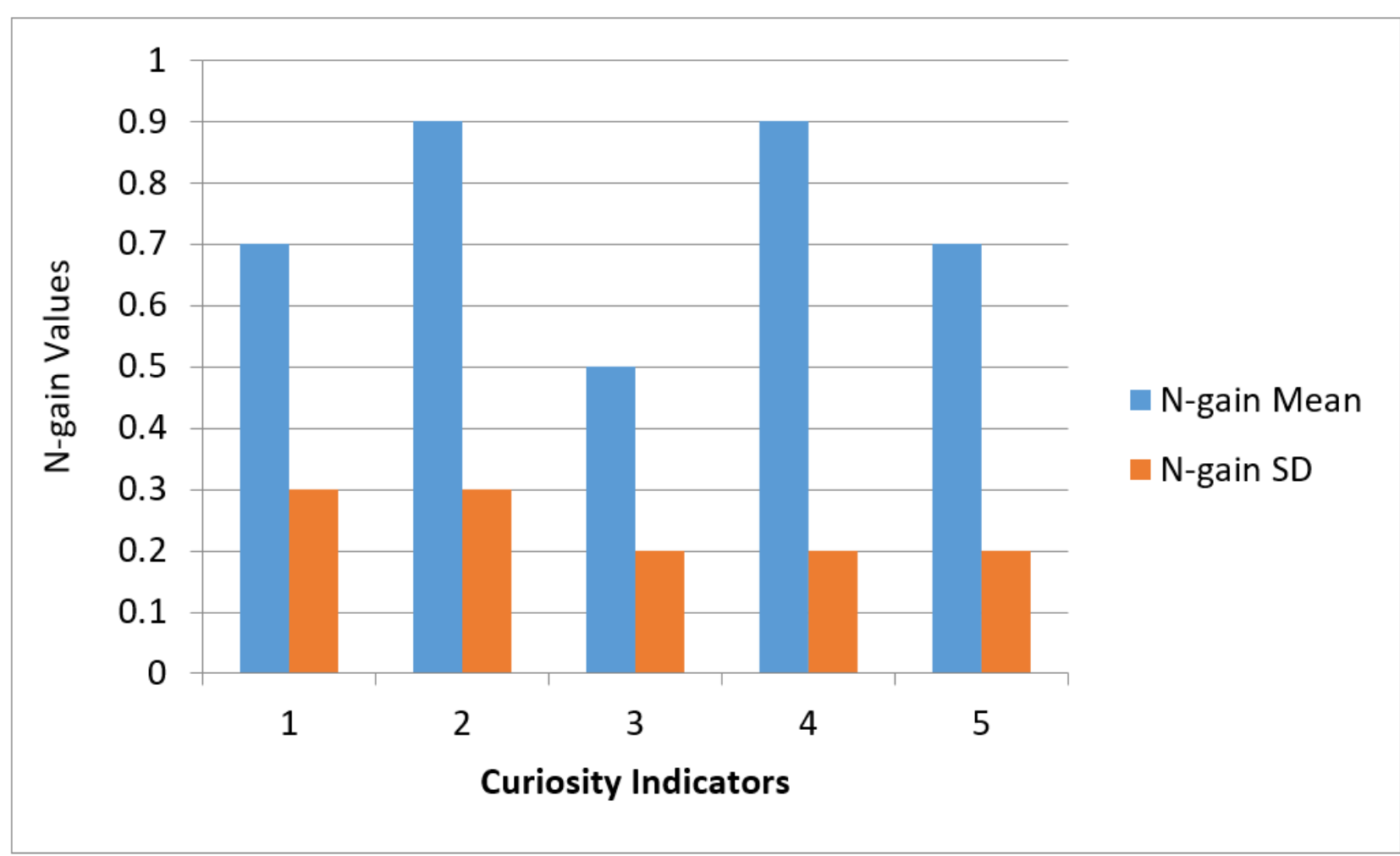

Figure 2. The graph of normalized gain for the mean and standard deviation of curiosity indicators

Table 2. A table of paired Samples $t$-test showing the $t$-value of curiosity indicators in SSRQ and the $t$-value from the TRS

\begin{tabular}{|c|c|c|c|c|c|c|c|c|c|}
\hline & & \multicolumn{5}{|c|}{ Paired Differences } & \multirow{3}{*}{$t$} & \multirow{3}{*}{$d f$} & \multirow{3}{*}{ Sig. } \\
\hline & & \multirow{2}{*}{ Mean } & \multirow{2}{*}{ SD } & \multirow{2}{*}{ SE } & \multicolumn{2}{|c|}{$95 \%$ C. I of the Difference } & & & \\
\hline & & & & & Lower & Upper & & & \\
\hline SSRQ & $\begin{array}{l}\text { Total of indicators A - } \\
\text { Total of the indicators }\end{array}$ & 20.766 & 10.561 & .933 & 18.918 & 22.613 & 22.246 & 127 & .000 \\
\hline TRS & POST-TEST - PRE-TEST & .941 & .911 & .070 & .802 & 1.079 & 13.427 & 168 & .000 \\
\hline
\end{tabular}

Dependent sample $t$-test was performed on the mean of indicators for pre and post-test results whereby mean and the standard deviation was $(M=94.977, S D=14.1390)$ before intervention while after the intervention mean and the standard deviation was $(M=115.742$, $S D=10.561), t(127)=22.246, p<0.0005$ as represented in Table 2 . The effect size was 0.80 which also confirmed that the intervention had a significant influence on learners' curiosity.

The statistical information obtained in the analysis of SSRQ was triangulated with the information obtained from both pre- and post-test TRS. The pre-test TRS were $(M=2.86, S D=0.908)$ while those of the post-test were
$(M=3.80, S D=0.573)$. The results from TRS also show an increase in students' curiosity after the seven weeks of intensive emphasis on the use of hands-on activities. Besides, the dependent sample $t$-test for TRS gave the $t$ value of $t(168)=13.427, p<0.0005$ with an effect size of 0.519 (Table 2). Triangulation between SSRQ and TRS results reveals that keeping other factors constant, the use of hands-on activities in chemistry lessons had an impact on students' curiosity. This is due to the changes manifested in the analysis of SSRQ and TRS as well as the observation, interviews, and FGDs results. 


\section{DISCUSSION}

Although triangulation of the findings both from qualitative and quantitative results reveal a significant development of students' curiosity, it is clear that more promising results could be obtained if the time for which the study was done would be extended. Looking at the difference in the mean and standard deviation of curiosity indicators before and after the intervention, the results indicate a slow increase in the intensity of students' curiosity developed due to the emphasis on the use of hands-on activities with time. this finding is similar to other past research findings (e.g., Fuad et al., 2018; Hirça, 2013; Pirttimaa et al., 2015) and different from research findings (e.g., Bransford et al., 2000; Harackiewicz et al., 2016; Jirout \& Klahr, 2012). However, interestingly it is evident from the study that the desire for students to search for instructional materials to facilitate their learning indirectly makes students remain in the learning atmosphere outside the school environment (Pirttimaa et al., 2015). This authentic learning (Bransford et al., 2000), can make students active and triggers their curiosity for learning.

Again, triangulation between the result from lesson observations, teacher interviews, and students FGDs shows that this research cleared the teachers' doubts on syllabus coverage and they gave their effort to ensure their students are in a positive mood of exploring the environment basing on the content learned. Although the whole process seemed to go against the normal routine in the beginning that both teachers and students are used to, but students' engagement in hands-on activities was helpful and students were inquisitive to know more. In this matter, teaching should not be an incidental craft to follow naturally from mastery of subject content but a highly complex blend of content understanding as well as practical skills (Opara \& Waswa, 2013). Also, soft skills in the affective domain of learning like curiosity should no more be ignored as they are very important than intelligence (Kidd \& Hayden, 2015; Lindholm, 2018). Therefore, it is important to note that students should be actively engaged in the learning process and allow them to be challenged and to reflect on their learning as well as link their prior knowledge to new knowledge. This is the better way to stir-up students' hunger for learning and desire to know more.

Besides, based on the fact that hands-on activities were emphasized more in the course of the intervention; it is evident from the findings that both students and teachers were seen to enjoy the strategy with time and become accustomed to hands-on activities as a productive teaching and learning strategies. Also, the continuous emphasis on hands-on activities enabled participants, both teachers and students to realize the way they can enhance the search for knowledge and enabled students to engage in various experiences that allow retention of the acquired knowledge. This is what
Von Stumm et al. (2011) consider being an epistemic curiosity. Not only retain the knowledge but also apply wherever it is supposed to be used. This was well demonstrated by students in one of the lesson observations in school A. Students were given four questions to discuss in their groups and the teacher chose randomly those who would represent their groups to solve these activities on board. Mostly, all students who represented their groups to do the given activities on-board demonstrated their enthusiasm for the activity and gave step-by-step procedures in answering the given questions. The desire of students to demonstrate the experiences acquired in their groups to the whole class depicts the development of perceptual curiosity (Litman \& Spielberger, 2003; Oudeyer et al., 2016) which was minimal among most of the students before the intervention.

Also, it is evident from the findings that the curious students were intrinsically motivated to complete a given task with more confidence, interest, and excitement. This in line with Borowske (2005); Gupta et al., (2019), and Ostroff (2016) who mentioned that curious students display a focused and exploratory inquisitiveness that motivates them to connect with what they know to what they do not know. It was again noted from the findings of this study that the curious students demonstrated the ability to explore their environment, work for the appropriate instructional materials, and fully engage in hands-on activities. Thus, both chemistry teachers and students need to adhere to the cultivated curiosity spirit so that they can achieve intended learning outcomes.

Likewise, the study findings revealed that when there is a close mentorship relationship between students and the teachers, the students' collaboration in lesson activities increases as well as the quality of the instructional materials produced. Also, students ought to understand the actions and instructions of their teachers in the ZPD so that they can internalize the information obtained (Glassman, 2001). Also, this is similar to the study findings which revealed the great impact of both teacher-student and student-student collaboration on the process of learning. When a student is in ZPD there is a higher chance to achieve the given task correctly (Lui, 2012). Therefore, similarly to what Vygotsky proposed this study revealed the importance of a teacher as a mentor in the classroom setting.

\section{CONCLUSION}

Taken together, the findings of this study contribute to the improvement of educational practices, instructional designs, and other related literature. Previously researchers viewed curiosity being a psychological trait that cannot be dealt with in an educational context. Little work has examined the connection between curiosity and learning in a 
classroom setting. The current study addresses this gap and guides the use of hands-on activities as part of learning instruction to stimulate curiosity in learning chemistry. If educators incorporate various hands-on activities especially by making students as chief controllers of their learning other than lessons being dictated by the teachers, they can create an environment that begets curious students. More broadly, this study found that sharing of success criteria and learning intentions for a particular lesson to be vital and should be highly emphasized among educators. This allows the students to familiarize themselves with the upcoming lesson before its commencement.

Overall, this study demonstrates the value of creating a learner-centered learning environment by students being at the center of their learning process. When students are highly engaged in hands-on activities can make them feel curious about what they are learning and enable them to better connect their prior knowledge with the new knowledge. We acknowledge that research that relates learning with students' curiosity is a body of work that still needs much attention especially following the interpretivist philosophical word view in this fastgrowing world of technology as it is fairly overlooked. Also, researchers planning for research studies in this research topic should dedicated enough time in their field work to obtain more reliable information which is transferable to similar research sample from real-world environment. We hope that this research serves as a taking-off point for other researchers, educators, and other educational practitioners who are seeking to design instructions that can stimulate students' curiosity.

Author contributions: All authors have sufficiently contributed to the study, and agreed with the results and conclusions.

Funding: This study is partially supported by the African Centre of Excellence for Innovative Teaching Mathematics and Science (ACEITLMS).

Declaration of interest: No conflict of interest is declared by authors.

Acknowledgements: We would like to express our gratitude to the African Centre of Excellence for Innovative Teaching Mathematics and Science (ACEITLMS) for the financial and authoritative support of this work as well as the following colleagues at the University of Rwanda: Angel Mukuka, Joseph Njiku, Kizito Ndihokubwayo, and Salma Saleh for all their advice.

\section{REFERENCES}

Affine, T. A. (2012). The zone of proximal development in early childhood education (Thesis). Laurea University of Applied Sciences.

Basit, T. (2003). Manual or electronic? The role of coding in qualitative data analysis. Educational Research, 45(2), 143-154. https://doi.org/10.1080/0013188 032000133548

Baxter, P., \& Jack, S. (2008). Qualitative case study methodology: Study design and implementation for novice researchers. The Qualitative Report, 13(4), $544-559$

Borowske, K. (2005). Curiosity and motivation-to-learn [Paper presentation]. ACRL Twelfth National Conference, Minneapolis, Minnesota, USA, April 7-10, 2005.

Bransford, J. D., Brown, A. L., \& Cocking, R. R. (2000). How people learn (Vol. 11). National Academy Press.

Bufkin, M. A. (2006). Qualitative Studies: Developing Good Research Questions. Online Submission. http:/ / eric.ed.gov/?id=ED494335

Coffey, A., \& Atkinson, P. (1996). Making sense of qualitative data: Complementary research strategies. Sage Publications, Inc. http://psycnet.apa.org/ psycinfo/1996-98161-000

Cohen, L., Manion, L., \& Morrison, K. (2007). Research methods in education (6th Ed). Routledge. https://doi.org/10.4324/9780203029053

Creemers, B. P. M., Kuptakions, $\Lambda .$, \& Sammons, P. (2010). Methodological advances in educational effectiveness research. Routledge. https://doi.org/ 10.4324/9780203851005

Creswell, J. W. (2008). Educational research: Planning, conducting and evaluating quantitative and qualitative research. Merril.

Creswell, J. W. (2014). Research design: Qualitative, quantitative, and mixed methods approaches (4th ed). SAGE Publications.

Fani, T., \& Ghaemi, F. (2011). Implications of Vygotsky's zone of proximal development (ZPD) in teacher education: ZPTD and self-scaffolding. ProcediaSocial and Behavioral Sciences, 29, 1549-1554. https:// doi.org/10.1016/j.sbspro.2011.11.396

Fuad, M., Deb, D., Etim, J., \& Gloster, C. (2018). Mobile response system: A novel approach to interactive and hands-on activity in the classroom. Educational Technology Research and Development, 66(2), 493-514. https://doi.org/10.1007/s11423-018-9570-5

Glassman, M. (2001). Dewey and Vygotsky: Society, experience, and inquiry in educational practice. Educational Researcher, 30(4), 3-14. https:/ / doi.org/ 10.3102/0013189X030004003

Goldkuhl, G. (2012). Pragmatism vs interpretivism in qualitative information systems research. European Journal of Information Systems, 21(2), 135-146. https:// doi.org/10.1057/ jis.2011.54

Gupta, P., Gupta, P., Sharma, Y., \& Sharma, Y. (2019). Nurturing Scientific Creativity in Science Classroom. Resonance, 24(05), 561-574. https:// doi.org/10.1007/s12045-019-0810-8

Harackiewicz, J. M., Smith, J. L., \& Priniski, S. J. (2016). Interest matters: The importance of promoting interest in education. Policy Insights from the 
Behavioral and Brain Sciences, 3(2), 220-227. https://doi.org/10.1177/2372732216655542

Hirça, N. (2013). The influence of hands on physics experiments on scientific process skills according to prospective teachers' experiences. European Journal of Physics Education, 4(1), 1-9.

Holstermann, N., Grube, D., \& Bögeholz, S. (2010). Hands-on activities and their influence on students' interest. Research in Science Education, 40(5), 743-757. https:/ / doi.org/10.1007/s11165-009-9142-0

Houghton, C., Casey, D., Shaw, D., \& Murphy, K. (2013). Rigour in qualitative case-study research. Nurse Researcher, 20(4), 12-17. https://doi.org/10.7748/ nr2013.03.20.4.12.e326

Jirout, J., \& Klahr, D. (2012). Children's scientific curiosity: In search of an operational definition of an elusive concept. Developmental Review, 32(2), 125160. https:// doi.org/10.1016/j.dr.2012.04.002

Kashdan, T. B., Rose, P., \& Fincham, F. D. (2004). Curiosity and exploration: Facilitating positive subjective experiences and personal growth opportunities. Journal of Personality Assessment, 82(3), 291-305. https://doi.org/10.1207/s15327752 jpa8203_05

Kelly, A. E., \& Lesh, R. A. (2000). Handbook of research design in mathematics and science education. Lawrence Erlbaum Associates. http:/ / search.ebsco host.com/login.aspx?direct=true\&scope $=$ site $\& \mathrm{db}=$ nlebk\&db=nlabk\&AN=19353

Khasawneh, O. M., Miqdadi, R. M., \& Hijazi, A. Y. (2014). Implementing pragmatism and John Dewey's educational philosophy in Jordanian public schools. Journal of International Education Research, 10(1), 37. https:/ / doi.org/10.19030/jier.v10i1.8465

Kidd, C., \& Hayden, B. Y. (2015). The Psychology and Neuroscience of Curiosity. Neuron, 88(3), 449-460. https:/ / doi.org/10.1016/j.neuron.2015.09.010

Kitzinger, J. (1995). Qualitative research. Introducing focus groups. BMJ: British Medical Journal, 311(7000), 299. https://doi.org/10.1136/bmj.311. 7000.299

Krueger, R. A., \& Casey, M. A. (2002). Designing and conducting focus group interviews. In Social Analysis, Selected Tools and Techniques (pp. 4-23).

Lamnina, M., \& Chase, C. C. (2019). Developing a thirst for knowledge: How uncertainty in the classroom influences curiosity affect, learning, and transfer. Contemporary Educational Psychology, 59, 101785. https:// doi.org/10.1016/j.cedpsych.2019.101785

Lee, K. L., Woh-Un, T., Ngoh-Khang, G. O. H., \& LianSai, C. (2001). The predicting role of cognitive variables in problem solving in mole concept. Chemistry Education Research and Practice, 2(3), 285301. https:// doi.org/10.1039/B1RP90029C
Lindholm, M. (2018). Promoting curiosity?: Possibilities and pitfalls in science education. Science $\mathcal{E}$ Education, 27(9-10), 987-1002. https://doi.org/ $10.1007 /$ s11191-018-0015-7

Litman, J. (2005). Curiosity and the pleasures of learning: Wanting and liking new information. Cognition $\mathcal{E}$ Emotion, 19(6), 793-814. https://doi.org/10.1080/ 02699930541000101

Litman, J. A., \& Spielberger, C. D. (2003). Measuring epistemic curiosity and its diversive and specific components. Journal of Personality Assessment, 80(1), 75-86.

https:/ / doi.org/10.1207/S15327752JPA8001_16

Lui, A. (2012). Teaching in the Zone: An introduction to working within the Zone of Proximal Development (ZPD) to drive effective early childhood instruction. Children's Progress, 1-10.

McLafferty, I. (2004). Focus group interviews as a data collecting strategy. Journal of Advanced Nursing, 48(2), 187-194. https:// doi.org/10.1111/j.13652648.2004.03186.x

Mertens, D. M. (2010). Research and evaluation in education and psychology: Integrating diversity with quantitative, qualitative, and mixed methods (3rd ed). Sage.

Morgan, D. L. (2014). Pragmatism as a paradigm for social research. Qualitative Inquiry, 20(8), 1045-1053. https:// doi.org/10.1177/1077800413513733

Olson, E. (1986). Measurement of curiosity in junior high school students (Dissertation). Iowa State University.

Opara, F., \& Waswa, P. (2013). Enhancing Students' Achievement in Chemistry through the Piagetian Model: The Learning Cycle. International Journal for Cross-Disciplinary Subjects in Education (IJCDSE), $4(4), \quad$ 1270-1278. https://doi.org/10.20533/ ijcdse.2042.6364.2013.0178

Ostroff, W. L. (2016). Cultivating curiosity in K-12 classrooms: How to promote and sustain deep learning. ASCD.

Oudeyer, P.-Y., Gottlieb, J., \& Lopes, M. (2016). Intrinsic motivation, curiosity, and learning: Theory and applications in educational technologies. In Progress in brain research (Vol. 229, pp. 257-284). Elsevier.

https:/ / doi.org/10.1016/bs.pbr.2016.05.005

Pirttimaa, M., Husu, J., \& Metsarinne, M. (2015). Uncovering procedural knowledge in craft, design, and technology education: A case of hands-on activities in electronics. Springer. https://doi.org/10.1007/ s10798-015-9345-9

Pluck, G., \& Johnson, H. L. (2011). Stimulating curiosity to enhance learning. GESJ: Education Sciences and Psychology, 2(19), 24-31.

Shahid, S., Bessarab, D., Howat, P., \& Thompson, S. C. (2009). Exploration of the beliefs and experiences of 
Aboriginal people with cancer in Western Australia: A methodology to acknowledge cultural difference and build understanding. BMC Medical Research Methodology, 9(1), 60. https://doi.org/ 10.1186/1471-2288-9-60

Shannon-Baker, P. (2016). Making paradigms meaningful in mixed methods research. Journal of Mixed Methods Research, 10(4), 319-334. https: / / doi.org/10.1177/1558689815575861

Sikandar, A. (2016). John Dewey and his philosophy of education. Journal of Education and Educational Development, 2(2), 191-201. https://doi.org/ 10.22555 /joeed.v2i2.446

Taber, K. S. (2018). The use of Cronbach's alpha when developing and reporting research instruments in science education. Research in Science Education,
48(6), 1273-1296. https:/ / doi.org/10.1007/s11165016-9602-2

Talja, S. (1999). Analyzing qualitative interview data: The discourse analytic method. Library $\mathcal{E}$ Information Science Research, 21(4), 459-477. https:// doi.org/10.1016/S0740-8188(99)00024-9

Von Stumm, S., Hell, B., \& Chamorro-Premuzic, T. (2011). The hungry mind: Intellectual curiosity is the third pillar of academic performance. Perspectives on Psychological Science, 6(6), 574-588. https:/ / doi.org/10.1177/1745691611421204

Yin, R. K. (2009). Case study research: Design and methods (4th ed). Sage Publications.

Zion, M., \& Sadeh, I. (2007). Curiosity and open inquiry learning. Journal of Biological Education, 41(4), 162169.

https:/ / doi.org/10.1080/00219266.2007.9656092 


\section{APPENDIX A}

\section{Lesson Observation Schedule}

Teacher's name:

School:

Date: Form three:

Topic: Sub-topic:

Time (actual used for lesson): from to:

Registered students for the stream: Total number: Number of girls: Number of boys: Actual students present: Total number: Number of girls: Number of boys:

Number of Desks and Chairs

Seating arrangement (give details)

\section{PART ONE: Planning}

Comment

Written Lesson Plan

(SMART ${ }^{1}$ objectives, logical development of the lesson, focused on learners, and learning. Photocopy/Scan of lesson plan will have to be attached)

Introduction of the lesson and clarification of learning objectives(learning intentions and criteria for success:

- sharing of objectives;

- stating and explains the criteria of success

Any other method used for clarification of objectives

\section{PART TWO: Teaching Strategy}

Teaching strategy used:

- Lecture (teacher-led);

- Lecture (interactive);

- Demonstration;

- Whole class discussion (questioning and answers);

- Hands-on activities (i.e., Group work - give details on group size; composition and manipulation of objects and symbols);

- Practical activities (experimentation);

- Any other strategy not listed

(Please provide examples, using verbatim quotes.)

\section{PART THREE: Learning resources used:}

- Chalkboard;

- Textbook;

- commercial materials e.g.;

- Low-cost material prepared for the lesson - state whether contextually and academically relevant;

- IT resources;

- Any other resources - give details.

(For the resources - the focus is on how they were used by pupils and teacher concerning the objectives of the lesson) PART FOUR A: Learning \& development of learners' curiosity

Describe how students' interaction with hands-on activities develop their curiosity in learning chemistry 
PART FOUR B: Role of the teacher to develop learners' curiosity

Provision of feedback to students

- Specific feedback to individual student

- General feedback to the class

How does the teacher guide students during hands-on activities to bring meaningful learning

(give details on teacher guidance)

PART FIVE: students' ability to develop instructional materials using low-cost materials

How are learners able to develop instructional materials?

What materials did students bring to class?

What additional materials did to teacher provide?

How did the teacher guide students on how to make and or use the instructional materials

What learning aids were learners able to develop?

(give details under each item)

Additional comments (e.g., factors that may have impacted on lesson delivery): 


\section{APPENDIX B}

\section{Students' Curiosity Self Reporting Questionnaire (SSRQ)}

Name of school.

Name....

Gender

\section{Class/stream}

Date

Read carefully each statement below and put a tick (V) to position yourself in a specific response which best represents you for the corresponding statement.

NO Statement

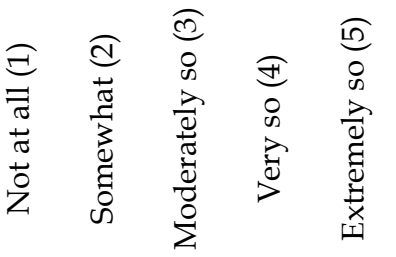

1. I would rather handle things than just looking on them

2. I ignore objects around me

3. I question a lot of things

4. New things capture my attention

$5 . \quad$ I want to find out things on my own

6. I enjoy handling new objects to explore them

7. I like to observe things that are going on in my environment

8. When I hear a strange voice, I want to know what is making them

9. $\quad$ Dislike changes

10. The complex is more exciting than simple

11. I like to touch paints and work with them

12. Bright colours capture my attention

13. I like to study easy things

14. I enjoy playing with silly putty, clay, and other things that can be shaped with my hands

15. I like to discover patterns in designs

16. I like to think about problems and try to solve them in my head

17. I like to study patterns that are puzzling and unusual

18. I like to take objects apart to find out more about them

19. School is boring

20. I like to ask about things that I do not fully understand

21. If I see a new machine In the room, I am likely to touch It

22. When I hear sudden claps of thunder, I like to look at the sky

23. I would rather solve a problem myself than be told how to do it by someone else.

24. I avoid complex situations

25. I learn about new objects by touching them

26. I like to notice everything that goes on around me

27. I like to explore things to find out information about them

28. I would like to know everything in a book

29. look at complex objects longer than I do simple objects

30. I like to cooperate with my fellow students

This students' self-reporting questionnaire is adapted from (Oslon, 1986) 


\section{APPENDIX C}

Teacher-Students Rating Evaluating Form for Learners Curiosity (TRS)

Name of School.

Class

..Date

According to Maw and Maw (1962), a learner is said to exhibit curiosity to the degree that:

1. Reacts positively to new, incongruous, or mysterious elements in the environment by moving toward them, by exploring them or by manipulating them,

2. Exhibits a need or a desire to know more about himself and/or his environment,

3. Scans his surroundings seeking new experiences, and

4. Persists in examining and exploring a problem and to know more about it.

DIRECTIONS:

Please list your students in alphabetical order. Then, based upon the above definition of curiosity, put a tick (V) to position each of your students with the corresponding column which best represents how curious each student is within the classroom.

Thank you!

This teacher-student rating scale is adapted from (Oslon, 1986)

\section{http://www.ejmste.com}

